reports show that the outcome of sexual contact with a care provider is negative in $90 \%$ of the cases and sometimes has far reaching consequences for physical and psychological functioning. ${ }^{357-9}$ There is no reason why this should be any different for the patients with whom our respondents had sexual contact. The discrepancy between doctors' perception of the consequences for the patient and what the patient herself may feel indicates a misconception held by the doctors involved, which makes it possible for them to enter into sexual contact in the doctor-patient relationship without any qualms. Special attention will have to be paid to this issue.

DESIRABILITY OF MORE ATTENTION TO SEXUAL ISSUES IN THE DOCTOR-PATIENT RELATIONSHIP

Ear, nose, and throat specialists had a different attitude towards questions on sexuality than gynaecologists. Most ear, nose, and throat specialists indicated that they wished to let the point rest (questions 11 and 12). That a clear majority were in favour of taking on an impartial counsellor for the patients and (to a smaller extent) for the doctors seems to be a contradiction, but it can be seen to fit within the framework of "the conspiracy of remaining silent," in which the problem is recognised but ignored and everyone tries not to disrupt the display of (ideal) correct behaviour to the people outside. Gynaecologists both recognise the problem and acknowledge that their professional society should acknowledge it.

This study shows that there are strong arguments for paying more attention to the subject of sexual contact in the doctor-patient relationship in the Netherlands.
In Britain, too, discussions on the topic would be welcomed. ${ }^{15}$

1 Kardener SH, Fuller M, Mensh IN. A survey 'of physicians' attitudes and practices regarding erotic and nonerotic contact with patients. Am $\mathcal{F}$ practices regarding erotic
Psychiatry 1973;130:1077-81.

2 Henderikx W, van Son-Schoones N. Lichamelijk contact in de hulpverlening. Deventer: Van Lochum Slaterus, 1984

3 Butler S, Zelen SL. Sexual intimacies between therapists and patients. Psychotherapy: theory, research and practice 1977;14:139-45

4 Holroyd JC, Brodsky AM. Psychologists' attitudes and practices regarding erotic and nonerotic physical contact with patients. Am Psychol 1977;32: 843-9.

5 Bouhoutsos J, Holroyd J, Lerman H, Forer BR, Greenberg M. Sexual intimacy between psychotherapists and patients. Professional psychology: research and practice 1983;14:185-96.

6 Gartrell N, Herman J, Olarte S, Feldstein M, Localio R. Psychiatrist-patient sexual contact: results of a national survey. I. Prevalence. Am $\mathcal{F}$ Psychiatry 1986;143:1125-31.

7 Burgess AW. Physician sexual misconduct and patients' responses. Am $\mathcal{F}$ Psychiatry 1981;138:1335-42.

8 Feldman-Summers S, Jones G. Psychological impacts of sexual contacts between therapists or other health care practitioners and their clients. $f$ between therapists or other health car
Consul Clin Psychol 1984;52:1054-61.

9 Pope KS. Therapist-patient sex syndrome: a guide for attorneys and subsequent therapists to assessing damage. In: Gabbard GO, ed. Sexual exploitation in professional relationships. Washington: American Psychiatric Press, 1989.

$10 \mathrm{Kardener}$ SH. Sex and the physician-patient relationship. Am $\mathcal{F}$ Psychiatry 1974;131:1134-6.

11 Smith S. The seduction of the female patient. In: Gabbard GO, ed. Sexual explotation in professional relationships. Washington: American Psychiatric Press, 1989.

12 Twenlow SW, Gabbard GO. The lovesick therapist. In: Gabbard GO, ed. Sexual exploitation in professional relationships. Washington: American Psychiatric Press, 1989.

13 Gutheil TG. Borderline personality disorder, boundary violations and patienttherapist sex: medicolegal pitfalls. Am $\mathcal{F}$ Psychiatry 1989;146:597-602.

14 Weijmar Schultz WCM, van de Wiel HBM. Sexual functioning after gynaecological cancer treatment [dissertation]. Groningen: State Univesity Groningen, 1991

15 Fisher N, Fahy T. Sexual relationships between doctors and patients. $f R S o c$ Med 1990;83:681-3.

(Accepted 2 April 1992)
Immunisation Division, PHLS Communicable Disease Surveillance

Centre, London NW9 5EQ

Mary E B Ramsay, research registrar

Norman T Begg, consultant epidemiologist

North East Essex Health Authority, Colchester CO4 5JR

Mala Rao, consultant in public health medicine

Correspondence to: Dr Begg.

BMf 1992;304:1534-6

\section{Symptoms after accelerated immunisation}

\author{
Mary E B Ramsay, Mala Rao, Norman T Begg
}

\section{Abstract}

Objective-To document the incidence of symptoms after accelerated immunisation with diphtheria-tetanus-pertussis vaccine.

Design-Controlled study of children immunised with adsorbed diphtheria-tetanus-pertussis vaccine at accelerated and standard schedules.

Setting-Colchester and north Hertfordshire.

Subjects-107 children scheduled to receive immunisation at 2, 3, and 4 months of age and 115 children scheduled to receive immunisation at $3,4 \frac{1}{2}$ to 5 , and $81 / 2$ to 11 months of age.

Main outcome measures-Parentally recorded symptoms, axillary temperatures, and size of local redness and swelling at the injection site during the seven days after immunisation.

Results - In general symptoms occurred less frequently with the accelerated schedule. Proportions of parents reporting axillary temperatures greater than $37.2^{\circ} \mathrm{C}$ or local redness or swelling greater than $2.5 \mathrm{~cm}$ after the third dose of vaccine were significantly reduced in the accelerated schedule group.

Conclusion-Immunisation at 2, 3, and 4 months of age is likely to cause fewer reactions than immunisation at $3,4 \frac{1}{2}$ to 5 , and $81 / 2$ to 11 months of age.

\section{Introduction}

In May 1990 an accelerated schedule of primary immunisation was introduced into the United Kingdom. The ages at which children received combined diphtheria-tetanus-pertussis vaccine and oral poliomyelitis vaccine were changed from $3,4 \frac{1}{2}$ to 5 , and $81 / 2$ to 11 months $^{1}$ to 2,3 , and 4 months. ${ }^{2}$ It is known that adsorbed diphtheria-tetanus-pertussis vaccine given at the old schedule can cause fever, swelling, and redness at the injection site and symptoms such as crying and irritability. ${ }^{34}$ The aim of this study was to document the incidence of mild systemic and local reactions to an accelerated schedule of primary diphtheria-tetanus-pertussis immunisation in the United Kingdom.

\section{Subjects and methods}

Children born between June 1989 and January 1990 were referred by health visitors and doctors in five general practices in central Colchester. Informed consent was obtained by a study nurse at a home visit. Children were then immunised at the surgery according to recommended procedure ${ }^{1}$ and at the preferred site of the immunising doctor or nurse. Adsorbed Wellcome diphtheria-tetanus-pertussis vaccine was administered, which had been distributed and stored according to routine practice in the district. Children who began the study were scheduled to receive their first dose at 8 weeks of age and subsequent doses at 12 and 16 weeks of age.

A historical control group was available of children born in north Hertfordshire between September 1986 and November 1987 who had taken part in a previous study to document reactions to Wellcome adsorbed diphtheria-tetanus-pertussis vaccine. These children were scheduled to receive immunisation at $3,4 \frac{1}{2}$ to 5 , and $81 / 2$ to 11 months. The immunisations were 
performed by doctors and practice nurses in 13 child health clinics or surgeries.

Using a diary, which was identical in the two groups, the parents recorded the child's axillary temperatures and size of any local redness or swelling at the injection site at specified times during a seven day follow up. After each dose the study nurse phoned or visited the home to ask parents about the presence or absence of specific symptoms.

The proportions of children with three or more symptoms, mild fever, or local reaction after each dose of vaccine were compared for both groups by using a $\chi^{2}$ test.

\section{Results}

The infants in each group were of similar birth weight (mean $3400 \mathrm{~g}$ in accelerated schedule group, $3300 \mathrm{~g}$ in control group). Of 107 children in the accelerated schedule group, $63(59 \%)$ were male, 53 $(50 \%)$ were born to first time parents, and $87(81 \%)$ were breast fed. Of 115 children in the control group, $70(61 \%)$ were male, $48(42 \%)$ were born to first time parents, and $86(75 \%)$ were breast fed. The groups differed, however, in the site of immunisation preferred.' In the control group 307 of 345 (89\%) doses were given into the thigh whereas general practitioners in Colchester preferred to use the buttock, 264 of 295 $(89 \%)$ immunisations being given at that site. In both groups immunisations were given with 0.5 by $16 \mathrm{~mm}$ needles.

In the accelerated schedule group study nurse follow up was performed at a mean of 25 hours (range 16-32 hours) after immunisation. Of the 295 doses administered, method of follow up was a home visit in $103(35 \%)$, telephone in $187(63 \%)$, and unspecified in five $(2 \%)$. In the control group follow up was performed by four study nurses at a mean of 26 hours (range 17-48 hours) after immunisation. Of the 345 doses administered, method of follow up was a home visit in $275(80 \%)$, telephone in $57(17 \%)$, clinic visit in four $(1 \cdot 1 \%)$, and unspecified in nine $(2 \cdot 6 \%)$.

In all, 107 children began diphtheria-tetanuspertussis immunisation with the accelerated schedule, but two discontinued pertussis immunisation after the first dose and completed with diphtheria-tetanus vaccine only. Only one of the children had a genuine contraindication to further doses of pertussis vaccine,$^{12}$ when he developed a temperature of $40.5^{\circ} \mathrm{C}$ on evening 2 after vaccination (measured by the mother). The second child was afebrile but seemed distressed with a high pitched cry on the first evening. Although the crying was neither prolonged nor inconsolable and therefore did not constitute a contraindication to further pertussis vaccine, ${ }^{12}$ the mother opted to complete with diphtheria-tetanus only vaccine.

Of the 105 children remaining in the accelerated schedule group, two did not receive the second dose and 16 did not receive the third dose of diphtheriatetanus-pertussis vaccine within eight weeks of the scheduled age and are excluded from analysis. Of these 18 children, all but one had completed diphtheriatetanus-pertussis immunisation by the age of 8 months; the remaining child had left the country and was lost to follow up. For those included in the analysis the median age at each dose was 11,16 , and 21 weeks in the accelerated schedule group and 14, 21, and 44 weeks in the control group.

Symptoms after immunisation-In general fewer children had a mild fever or a local reaction in the accelerated schedule group than in the standard schedule group (table). After the third dose there were significant reductions in the proportions of parents recording axillary temperatures above $37 \cdot 2^{\circ} \mathrm{C}$ $(p=0.00004)$ and local swelling $(p=0.00003)$ or redness $(p=0.0004)$ greater than $2.5 \mathrm{~cm}$ diameter at the injection site. Local swelling larger than $2.5 \mathrm{~cm}$ after the first dose of vaccine only was reported more often in the accelerated schedule group than in the control group $(\mathrm{p}=0.002)$.

\section{Discussion}

One of the main reasons for introducing the accelerated schedule in the United Kingdom was the hope that earlier immunisation would facilitate an improvement in vaccine coverage. ${ }^{2}$ This had been suggested because attendance of young children at child health clinics falls beyond the age of 7 months. As reactions to immunisation may contraindicate further doses ${ }^{12}$ and because parental concern about vaccine safety may reduce compliance with vaccination programmes $^{6}$ it is important that any new schedule should not cause more reactions than the schedule it replaces.

In this study only two of 107 children in the accelerated schedule group failed to complete immunisation with diphtheria-tetanus-pertussis vaccine, and only one of these had a genuine contraindication to further pertussis immunisation. Although 18 (17\%) children did not complete immunisation within eight weeks of the scheduled age, delay in completing immunisation was also commonly observed with the prolonged schedule. ${ }^{7}$ It is reassuring that all but one of the children in this study had completed immunisation by the age of 8 months.

Mild reactions after adsorbed diphtheria-tetanuspertussis vaccine have been reported when children are immunised at around $3,4 \frac{1}{2}$ to 5 , and 8 to 10 months of age. After immunisation the proportion of children developing a mild fever $^{3}$ or a large local reaction ${ }^{4}$ increases with successive doses. In this study we showed that adverse events after accelerated immunisation with adsorbed diphtheria-tetanus-pertussis vaccine occurred less frequently than in children immunised according to a prolonged schedule. This may reflect two factors, either the younger age of the children or the fact that the buttock was the preferred injection site. A comparison of symptoms after immunisation in the United Kingdom showed no effect of injection site, ${ }^{4}$ and a study of primary immunisation in the United States (which failed to adjust for the effect of dose) concluded that no injection site was consistently associated with a lower rate of all systemic or local reactions. ${ }^{8}$ In our study after the third dose, when age differed most between the two

Numbers (percentages) of parents reporting symptoms after diphtheria-tetanus-pertussis vaccine

\begin{tabular}{|c|c|c|c|c|c|c|c|c|}
\hline & \multicolumn{2}{|c|}{$\begin{array}{c}\text { Axillary temperature } \geqslant 37 \cdot 2^{\circ} \mathrm{C} \\
\text { on evening } 2\end{array}$} & \multicolumn{2}{|c|}{$\begin{array}{l}\text { Redness }>2.5 \mathrm{~cm} \text { diameter at } \\
\text { injection site on evening } 2\end{array}$} & \multicolumn{2}{|c|}{$\begin{array}{l}\text { Swelling }>2.5 \mathrm{~cm} \text { diameter at } \\
\text { injection site on evening } 2\end{array}$} & \multicolumn{2}{|c|}{$\begin{array}{l}\text { Three or more symptoms in } \\
\text { first } 24 \text { hours }{ }^{\star}\end{array}$} \\
\hline & $\begin{array}{l}\text { Accelerated } \\
\text { schedule }\end{array}$ & $\begin{array}{l}\text { Standard } \\
\text { schedule }\end{array}$ & $\begin{array}{l}\text { Accelerated } \\
\text { schedule }\end{array}$ & $\begin{array}{l}\text { Standard } \\
\text { schedule }\end{array}$ & $\begin{array}{l}\text { Accelerated } \\
\text { schedule }\end{array}$ & $\begin{array}{l}\text { Standard } \\
\text { schedule }\end{array}$ & $\begin{array}{l}\text { Accelerated } \\
\text { schedule }\end{array}$ & $\begin{array}{l}\text { Standard } \\
\text { schedule }\end{array}$ \\
\hline First dose & $22 / 101(22)$ & $26 / 114(23)$ & $19 / 103(18)$ & $15 / 112(13)$ & $33 / 102+(32)$ & $16 / 112+(14)$ & $27 / 105(26)$ & 24/99 (24) \\
\hline Second dose & $24 / 97(25)$ & $40 / 113(35)$ & $17 / 99(17)$ & $35 / 113(31)$ & $26 / 99(26)$ & $31 / 113(27)$ & $22 / 100(22)$ & $31 / 110(28)$ \\
\hline Third dose & $18 / 80+(23)$ & $57 / 110+(52)$ & $21 / 81+(26)$ & $58 / 111+(52)$ & $24 / 80+(30)$ & $56 / 111+(50)$ & $13 / 73(18)$ & $28 / 105(27)$ \\
\hline
\end{tabular}

* Any of following symptoms: vomiting, off food, more sleepy, irritable, crying more than usual, disturbed night.

tDifference between accelerated and standard schedule groups significant at $\mathrm{p}<0.01\left(\gamma^{2}\right.$ test $)$. 
groups, systemic and local reactions were reported consistently less often in the accelerated schedule group. This suggests that the observed differences were due to the age difference between infants receiving each schedule.

Our study suggests that an accelerated schedule of immunisation is likely to cause fewer reactions than the prolonged schedule. We advise the continued close monitoring of vaccine coverage and adverse event reports after implementing accelerated immunisation.

We thank Dr Elizabeth Miller for the control data and acknowledge the help of Mrs Kathleen Cannings and the doctors, staff, and attached health visitors at Mile End, 3 and 81a East Hill, 76 Malden Road, $19^{\circ}$ Creffield Road, and 80 North Hill plus all the parents and babies who participated in the study.
Department of Health and Social Security. Immunisation against infectious disease. London: HMSO, 1988

2 Department of Health. Immunisation against infectious disease. London: HMSO, 1990.

3 Waight PA, Pollock TM, Miller E, Coleman EM. Pyrexia after diphtheria tetanus/pertussis and diphtheria/tetanus vaccines. Arch Dis Child 1983;58 $921-33$

4 Pollock TM, Miller E, Mortimer JY, Smith G. Symptoms after primary immunisation with DTP and DT vaccine. Lancet 1984;ii: 146-9.

5 Jones AE, Johns A, Magrath DI, Melville-Smith M, Sheffield F. Durability of immunity to diphtheria, tetanus and polio after a three dose immunisation schedule completed in the first eight months of life. Vaccine 1989;7:300-2.

6 Peckham C. National immunisation study: factors influencing immunisation uptake in childhood. Horsham: Action Research for the Crippled Child, 1989.

7 Begg NT, Gill ON, White JM. COVER (cover of vaccinations evaluated rapidly): description of the England and Wales scheme. Public Health 1989;103:81-9.

8 Barraff LJ, Cody CL, Cherry JD. DTP-associated reactions: an analysis by injection site, manufacturer, prior reactions, and dose. Pediatrics 1984;73: $31-6$

(Accepted 27 April 1992)

\title{
New rapid test for prenatal detection of trisomy 21 (Down's syndrome): preliminary report
}

\author{
Thue Bryndorf, Britta Christensen, John Philip, Winnie Hansen, Kathy Yokobata, Nga Bui, \\ Candy Gaiser
}

Abstract

Objective - To devise and evaluate a rapid screening method for detecting trisomy 21 (Down's syndrome) in samples of uncultured amniotic fluid cells.

Design-Non-radioactive in situ hybridisation with HY128, a 500000 base pair yeast artificial chromosome probe specific for chromosome 21 . Blinded study of 12 karyotypically normal amniotic fluid samples and eight samples trisomic for chromosome 21.

Setting-Cytogenetic and obstetric services at a tertiary referral centre, Copenhagen.

Main outcome measures - Time necessary to complete the test. Proportion of cell nuclei containing two and three hybridisation signals in karyotypically normal and abnormal amniotic fluid samples.

Results-The test could be completed within three to four days after amniocentesis. In the normal samples a mean of $73 \%$ (range $61-82 \%$ ) of the amniotic cell nuclei showed two hybridisation signals and $6 \%(0-18 \%)$ showed three signals. By contrast, among the trisomic samples $29 \%(19-38 \%)$ of the nuclei exhibited two signals and 48\% (31-60\%) showed three signals.

Conclusion - The technique clearly distinguished between normal and trisomic samples. Prenatal diagnosis with in situ hybridisation with chromosome specific probes was fast and may make it possible to screen for selected, aneuploidies. However, the technique is still at a preliminary stage and needs further evaluation and refinement.

\section{Introduction}

Non-radioactive in situ hybridisation has made it feasible to obtain cytogenetic information from interphase cells. In this technique chemically modified probe DNA, specific for a certain chromosome, is mixed with chromosomal DNA after denaturation to separate the double strands. After the probe and chromosomal DNA have combined the probe is conjugated with fluorescent molecules which can then be visualised by fluorescence microscopy.

Several studies have shown that non-radioactive in situ hybridisation with DNA probes can be used to study aberrations in the number of copies of chromosomes in cultured amniocytes. ${ }^{14}$ We have previously reported the use of two centromere specific probes to determine the number of copies of chromosomes 1 and 18 in samples of uncultured amniocytes. ${ }^{4}$ Another study has described enumeration of the $\mathrm{Y}$ chromosome in uncultured amniocytes by in situ hybridisation with a probe specific for the long arm of this chromosome. Similarly, we have found the centromere specific, chromosome $\mathrm{X}$ specific probe $\mathrm{pBamX}^{6}$ and a probe specific for a locus on the long arm of chromosome $13^{78}$ are suitable for in situ hybridisation on uncultured amniocytes (unpublished data).

In this preliminary study we used in situ hybridisation with a large probe specific for chromosome 21 to try to distinguish between samples of uncultured amniocytes with normal and trisomic karyotypes.

\section{Materials and methods}

CELLS

Amniotic fluids were sampled at 14-21 weeks' gestation from women at moderate risk of a fetus with chromosome abnormalities. Women carrying fetuses with karyotypically confirmed Down's syndrome had amniotic fluid drawn in conjunction with termination of pregnancy at 13-22 weeks' gestation. Informed consent was given by all the women. Amniocytes were isolated and prepared for in situ hybridisation as previously described. ${ }^{4}$ Twelve samples from fetuses with a normal karyotype and eight samples from fetuses with trisomy 21 were further analysed as described below

Cultured amniocytes and mesenchymal cells from the chorionic villi were prepared by standard procedures and used for interphase and metaphase studies.

PROBES

The yeast artificial chromosome HY128 contains a human chromosome 21 specific DNA fragment of about 500000 base pairs. HY128 was obtained from M-C Potier and M Goedert (Medical Research Council, Cambridge, United Kingdom).

DNA from the HY128 yeast artificial chromosome and the host was used as the chromosome 21 probe and was prepared essentially as described by Burke and Olson. ${ }^{9}$ The probe was labelled with biotin-14-dATP (Bethesda Research Laboratories, Gaithersburg, Maryland, USA). 